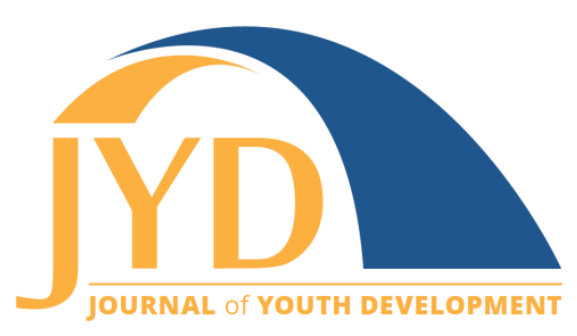

http://jyd.pitt.edu/ | Vol. 15 Issue 3 DOI 10.5195/jyd.2020.947 | ISSN 2325-4017 (online)

\title{
Dual Language Learning and Educational Success for Youth
}

\author{
Suzanne Le Menestrel \\ National Academies of Sciences, Engineering, and Medicine \\ slemenestrel@nas.edu
}

\begin{abstract}
Effectively educating children and youth who are learning English as their second language is a national challenge with consequences both for individuals and for American society. Despite their potential, many English learners are struggling to meet the requirements for academic success jeopardizing their prospects for success in postsecondary education and the workforce. This article is based on a consensus report from the National Academies of Sciences, Engineering, and Medicine, Promoting the Educational Success of Children and Youth Learning English: Promising Futures published in 2017, and briefly reviews language development among dual language and English learners and the development of English proficiency. The article also discusses promising and effective practices for children and youth learning English in grades pre-K through 12. The needs of dual language learners and English learners with disabilities and those of long-term English learners are also discussed.
\end{abstract}

Key words: English learners, dual language learning, English as a second language, bilingualism

\section{Introduction}

Effectively educating children and youth who are learning English as their second language is a national challenge with consequences both for individuals and for American society. Despite their potential, many English learners are struggling to meet the requirements for academic success jeopardizing their prospects for success in postsecondary education and the workforce. This article is based on a consensus report from the National Academies of Sciences,

(cc) $\mathbf{E Y}$ New articles in this journal are licensed under a Creative Commons Attribution 4.0 License. This journal is published by the University Library System, University of Pittsburgh and is cosponsored by the University of Pittsburgh Press. The Journal of Youth Development is the official peer-reviewed publication of the National Association of Extension 4-H Agents and the National AfterSchool Association. 
Engineering, and Medicine, Promoting the Educational Success of Children and Youth Learning English: Promising Futures published in 2017. ${ }^{1}$

The report addresses children who are dual language learners or DLLs (children ages birth to age 5 who are learning two languages at once and who are not in the pre-K-12 education system) and English learners or ELs (children and youth ages 5 to 21 in the pre-K-12 education system whose primary language is not English and who are learning English as a second language). The focus of this article will be primarily on youth in the pre-K-12 education system or ELs. This report examines what research evidence reveals about learning English from early childhood through high school, identifies effective practices for educators to use, and recommends steps policymakers can take to support high-quality educational outcomes for children and youth who are learning English.

\section{Who are DLLs and ELs?}

DLLs and ELs are demographically diverse. They vary in their home language, language abilities, race and ethnicity, immigration circumstances, generational status in the United States, geographic distribution, academic achievement, parental characteristics, and socioeconomic resources, disability status, and other characteristics. The majority of children in the U.S. English-learner population are born in the United States and are birthright citizens. Many ELs grow up in contexts that expose them to many risk factors such as low levels of parental education, low family income, refugee status, and homelessness, which can harm their school success, especially when these disadvantages are concentrated. Nevertheless, the cultures, languages, and experiences of ELs are highly diverse and represent assets for their development, as well as for the nation.

${ }^{1}$ This article reproduces text verbatim and paraphrases Promoting the Educational Success of Children and Youth Learning English: Promising Futures released in 2017 and used with permission from the National Academies Press, Washington, DC. Suggested citation for the full report: National Academies of Sciences, Engineering, and Medicine. 2017. Promoting the Educational Success of Children and Youth Learning English: Promising Futures. Washington, DC: The National Academies Press. https://doi.org/10.17226/24677. The report was authored by the Committee on Fostering School Success for English Learners: Toward New Directions in Policy, Practice, and Research. Appreciation goes to Ruby Takanishi, Lily Wong Fillmore, and Natacha Blain for their reviews of earlier drafts of this article and to the full committee for authoring this report. This study was funded by the Administration for Children and Families; the Foundation for Child Development; the Health Resources and Services Administration; the Heising-Simons Foundation; the McKnight Foundation; and the U.S. Department of Education. 


\section{A Word About Language Development}

Scientific evidence points to a universal, underlying capacity to learn two languages as easily as one. Children who are dual language learners have an impressive capacity to manage their two languages when communicating with others. They can differentiate when to use each language based on the language known or preferred by the people to whom they are speaking, for example. Recent research evidence also points to cognitive advantages, such as the ability to plan, regulate their behavior, and think flexibly for children and adults who are competent in two languages. Learning and using two languages enhances executive functioning, the ability to plan, control one's attention, regulate one's behavior, and think flexibly. Bilinguals often exhibit a broad set of advantages that are related to the ability to control their focus of attention. They may also have advantages in spatial and verbal working memory and other components of executive functioning that emerge as early as 18 months of age. Such advantages are observed most commonly among bilinguals who became highly proficient in both of their languages at early ages (Gordon, 2016). However, ELs are at risk of losing their first language when exposure to English begins early-during the preschool or early years. This is the case even when youth are in dual language programs. Loss of or reduced competence in a child's first language results in reduced levels of bilingual competence, and commensurately, the advantages associated with bilingualism-cognitive enhancements, improved self-esteem, and job-related opportunities associated with competence in English and another language or languages.

The competence with which children learn their primary language and English varies considerably among individuals, which may be explained by multiple factors-for example, early versus late exposure to a second language (e.g., Dupoux et al., 2010; Meisel, 2011; OrtizMantilla et al., 2010), parents' immigrant generational status and years in the United States, socioeconomic status, exposure to the risks of poverty, status of the first language in the community, and neighborhood features. Parents from different cultural communities have differing views and practices concerning their role as teachers of their children and how much they communicate with their children. These differences influence children's language development. Early exposure to a second language (before approximately 3 years of age) is consistently associated with better language skills in that second language. Children exposed to two languages simultaneously demonstrate the same developmental trajectory in each language as that seen in monolingual children, provided they have adequate exposure to each language. 
A key question has been the extent to which children's ability in the first language supports or hinders their acquisition of a second. Some immigrant parents may fear that talking with their child in the first language will slow or interfere with English acquisition; teachers also express this concern. But building a strong base in a child's home language facilitates the development of skills in a second and even third language. Use of the first language in various settings is associated with the development of a healthy ethnic identity in early childhood and lessens the potential negative psychological effects that can occur if the first language is lost, such as weakening relationships with parents and other family members. Also, research indicates that children's language development benefits when adults talk to them in the language in which the adults are most competent and with which they are most comfortable.

\section{Development of English Language Proficiency in Grades Pre-K to12}

Policies and practices for educating ELs in our country have been driven in the past by beliefs and attitudes about how best to ensure that they acquire high levels of functional proficiency in English as quickly as possible (Espinosa, 2013). It is important to note that language proficiency is not necessarily the only or even the most important barrier to academic success among ELs. Depending on the background of specific children or groups of ELs, their educational success can be jeopardized by poverty; poor health; trauma linked to immigration; cultural differences between home and school; state, district, and school policies and practices; the quality of educational materials, instruction, and curriculum; teachers' attitudes; and inadequate teacher preparation.

The question of how long it does, or should take ELs to achieve proficiency in English so they can benefit from participation in classrooms in which English is the language of instruction has engaged researchers, policymakers, the media, and the public since the 1974 Supreme Court decision in Lau v. Nichols granted linguistic accommodations to students with limited proficiency in English. Understanding the time it takes ELs to develop English language proficiency is critical to the discussion of how to best to educate youth for several reasons:

1. States are required to develop and implement identification and classification systems for ELs whose level of proficiency is deemed too low for them to be educated in mainstream classrooms without additional support.

2. There is growing recognition that educational research on and education policies and practices concerning English language development of ELs need to distinguish between 
language for social communication and language for academic purposes. Proficiency in language for academic purposes requires that students be competent at performing sophisticated "language functions" such as the ability to present a logical argument, question or explain, and evaluate alternative points of view.

3. Academic language differs from one subject to another.

It can take from 5 to 7 years for students to learn the English necessary for participation in a school's curriculum without further linguistic support. This is due in part to the increasing language demands of participation in school learning over time, especially concerning the language used in written texts beyond the early primary years. Students may require help with English through the upper elementary and middle school grades, particularly in acquiring proficiency in the academic uses of English. While of critical importance, "academic language" has been difficult to define, and is variously characterized in functional, grammatical, lexical, rhetorical, and pragmatic terms. As a result, efforts to support its development in classrooms have been inconsistent, just as efforts to assess its development have been problematic. Several factors influence reclassification rates ${ }^{2}$ among ELs in grades $\mathrm{K}-12$. These include gender, language background, socioeconomic status, being foreign-born versus being born in the United States, and English proficiency at school entry.

\section{DLLs and ELs with Disabilities}

About 9\% of dual language learners and English learners have disabilities-about 350,000 children. Dual language learners and English learners are less likely than other students to be referred to early intervention and early special education programs, with potentially serious consequences. Early childhood education, home visiting, health, and other professionals may not be identifying DLLs and ELs with special needs who could benefit from such programs.

There are four major common myths and correct facts about DLLs and ELs with disabilities:

\section{Consequences of exposure to multiple languages}

Myth: Children with language difficulties get confused and overwhelmed by learning or being exposed to more than one language.

\footnotetext{
${ }^{2}$ According to the Education Commission of the States, reclassification "occurs when it is determined (typically through English language proficiency exam scores) that the student no longer requires EL services, sometimes called 'exiting.' This should happen when the students are proficient in English and no longer need language instruction." (See http://ecs.force.com/mbdata/mbquestNB2?rep=ELL1407)
} 
Fact: DLLs/ELs differentiate their languages from an early age and there is no evidence that those with disabilities get confused or overwhelmed or have additional difficulties with or negative consequences from learning two (or more) languages.

\section{Code switching}

Myth: Code-switching (switching between languages in a single conversation) reflects the confusion and inability of children with disabilities to keep their languages separate. Therefore, it is a sign or cause of language impairment ${ }^{3}$ in DLLs/ELs.

Fact: Code-switching, such as "Spanglish," is a normal and grammatical behavior in all DLLs/ELs, including those with disabilities, and it can help them communicate effectively. It is equally present in typically developing children and should not be interpreted as a sign of language impairment.

\section{Language learning capacity}

Myth: Exposure to two or more languages will cause "cognitive overload" and result in reduced capacity to learn English in DLLs with language impairment.

Fact: In reality, claims that DLLs with language impairment have smaller vocabularies than monolinguals with language impairment are based on measures of lexical inventories only in the second language (typically English). When the vocabulary size of both languages is assessed, no evidence suggests that DLLs have smaller vocabularies than monolinguals with comparable language impairment.

\section{Home language}

Myth: Parents should stop using the home language to maximize children's chances of learning the predominant language.

Fact: Studies have shown that when mothers speak to their children in their nondominant language, there is overall less verbal communication in the home. This can pose a problem because children who receive rich linguistic input develop larger vocabularies. Moreover, for DLL/EL children with autism spectrum disorder, research findings suggest that speaking the home language facilitates social interaction, and in turn language and social development. In DLLS/ELs with emotional or behavioral disorders, maintaining the home language grants access to protective resources important for social, behavioral, and emotion regulation and facilitates the development of ethnic cultural identity.

\footnotetext{
${ }^{3}$ Language impairment is a persistent difficulty acquiring and using language across modalities due to deficits in production and/or comprehension.
} 


\section{Dual Language Learning and Educational Success}

\section{Long-Term English Learners}

Some ELs fail to be reclassified as English-proficient even after many years of schooling in English. These youth are often referred to as long-term English learners or LTELs. They are most commonly ELs who have not been reclassified after 7 years, though there is a lack of a common definition. LTELs have attracted increased attention in recent years because they represent a sizeable segment of the EL population (e.g., Menken, 2013). LTELs are often proficient in everyday uses of oral English but have low levels of proficiency in academic language and literacy in both English and their first language. Commonly, LTEL students reach a plateau at intermediate or lower levels of language proficiency (Olsen, 2010). LTELs are to be distinguished from other struggling high school-aged ELs who are new arrivals and are often refugees who have experienced interrupted or limited formal education (Boyson \& Short, 2003; Menken, 2013). LTELs often have had inconsistent educational programming and have experienced weak, no, or inappropriate language education programs; curriculum and learning materials that are not designed for their needs; and limited access to the full curriculum.

\section{Promising and Effective Practices for English Learners in Grades Pre-K to 12}

Attention to how ELs are faring in grades pre-K to 12 comes at a pivotal time in American schools, when schools throughout the nation are teaching to higher curricular standards in core subject areas, including math, English language arts, and science. All students, including ELs, are expected to engage with academic content that is considerably more demanding than it used to be, and they must now demonstrate deeper levels of understanding and analysis of that content. ELs face the tasks of simultaneously achieving English proficiency and mastering grade-level academic subjects. Two broad approaches are used to teach English to ELs in grades K-12: (a) English as a second language (ESL) approaches in which English is the predominant language of instruction; and (b) bilingual approaches, in which both English and students' home languages are used for instruction. Syntheses of evaluation studies that compare outcomes for ELs instructed in English-only programs with outcomes for ELs instructed bilingually find either that there is no difference in outcomes measured in English or that ELs in bilingual programs outperform ELs instructed only in English. Two recent studies that followed students for sufficient time to gauge the longer-term effects of language of instruction on EL outcomes find benefits for bilingual compared with English-only approaches (Umansky \& Reardon, 2014; Valentino \& Reardon, 2015). 


\section{Children and Youth in Elementary School}

Research has identified seven practices or guidelines for educating ELS in grades $\mathrm{K}-5$ :

1. Provide explicit instruction in literacy components.

2. Develop academic language during content-area instruction.

3. Provide visual and verbal supports to make core content comprehensible.

4. Encourage peer-assisted learning opportunities.

5. Capitalize on students' home language, knowledge, and cultural assets.

6. Screen for language and literacy challenges and monitor progress.

7. Provide small-group academic support in literacy and English language development for students.

\section{Youth in Middle School}

Young adolescent ELs enter middle school (typically ages 10 to14) at what can be a turning point in their educational trajectory. Whether they are classified during their middle school years as long-term English learners or are newcomers to American classrooms, ELs face new challenges in middle school that influence their opportunities to learn both English and the rigorous academic subject matter required by today's higher state standards. Middle schools are typically larger places for youth to navigate relative to primary schools. Many ELs move from having one teacher in primary school to having several teachers, each of whom is responsible for specific academic disciplines. ELs must adapt to different teachers with different approaches to subject matter instruction while mastering academic English terms tied to specific disciplines (Suárez-Orozco et al., 2008).

Some middle school ELs are placed in "sheltered" classes for long periods where they are segregated from other students, with restricted access to grade-level academic courses and English-proficient peers. This practice can have stigmatizing effects (Rumberger et al., 2006; Valdés, 2001; Walqui et al, 2010) and inhibit the development of their language proficiency, their grade-level knowledge and skills, and their motivation to learn in school. At the same time, young adolescents are experiencing normative neurobiological, social, and cognitive changes (See National Academies of Sciences, Engineering, and Medicine, 2019) in which peer groups, youth, and community organizations can become significant influences. All of these convergences are daunting (Eccles, 2008) but are likely to be compounded for ELs. 
Young adolescent ELs' degree of success in meeting these requirements will have consequences for their career and postsecondary education prospects. Research points to three promising practices for middle school EL instruction:

1. Teachers should use a youth's first language to develop academic English in specific content areas in middle schools.

2. Teachers should use collaborative, peer-group learning communities to support and extend teacher-led instruction.

3. Texts and other instructional materials should be at the same grade level as those used by English-proficient peers.

Literacy engagement is critical during the middle school grades. During these grades, students are required to read and learn from advanced and complex grade-level texts. For ELs, this problem is acute because instructional support for long-term ELs tends to emphasize skills instead of dealing with the barriers to their motivation to learn, engagement in the classroom, and literacy engagement.

Research on ELs' language and academic subject learning in middle school is consistent with findings from studies conducted with children in the previous grades and supports the identification of promising practices during the primary grades (pre-K to 5). However, the developmental needs of young adolescent ELs-specifically their cognitive and social development-and their adaptation to a different organizational structure and expectations for student independence in middle school are important factors to consider in designing and implementing instructional strategies in middle school. The processes of identity formation and social awareness, which increase during adolescence, point to the importance of teacher beliefs about ELs and their attitudes toward learning English when working with middle school ELs.

Furthermore, ELs' learning experiences in middle school classrooms can be a significant turning point in their educational trajectories. Disengagement from education can be associated with chronic absences from classes, identification for special education services, suspensions related to behavioral problems, or eventual dropping out of school (Burke, 2015). Moreover, teachers' beliefs about students' potential can influence the quality of the programs they are offered in middle school (Valdés, 2001). In an ethnographic study of middle school ELs, it was found that the social context of middle schools, shaped by the sociodemographic characteristics of the ELS and how teachers perceive their capacities for learning both English and academic subjects, can 
result in different classroom learning experiences and outcomes (Valdés, 2001; see also Kim \& Viesca, 2016).

\section{Youth in High School}

The structure and large size of some high schools can make the transition from middle school especially difficult for ELs (Egalite \& Kasida, 2016; Leithwood \& Jantzi, 2009; Nield, 2009). Some high school ELs may be newcomers to American schools with varying experiences of formal education in their countries of origin and may have experienced disruption in school or trauma as a result of their migration. Other EL high school students may have been in American schools for years.

The focus of most newcomer programs is to better serve ELs with no to low English language proficiency and to work with ELs with low literacy in their first language. While some programs focus only on English, however, others provide some primary language support and ESL.

Newcomer programs are specially designed for immigrant high school students new to the United States, but they vary widely in their services. These can range from

- short-term (a month or a summer) to longer-term (1 to several years);

- school site-based to separate site;

- focus on academic skills to inclusion of supplemental services such as health, counseling, and mental health services;

- elementary to secondary; and

- after-school to half- to full-day.

High school ELs must meet graduation requirements as well as state standards for "career and college readiness" and enroll in nonremedial classes that prepare them for postsecondary education. In some schools, ELs are blocked from access to a large proportion of the core curriculum, electives, and advanced placement classes because they are locked into English language development (ELD) and/or intervention classes, sometimes for the whole school day (Callahan, 2005). High school ELs also face several developmental challenges such as navigating the social and cultural contexts at their school, discrimination (e.g., DeGarmo \& Martinez, 2006), and other challenges. While ELs' high school graduation rates are growing with a rate of $66.9 \%$ in $2015-2016$, they are still much lower than the overall high school graduation rate (U.S. Department of Education, Office of English Language Acquisition, 2018). 
Research on instructional practices for ELs in high school is less available than that on practices for elementary school. Nonetheless, recommendations for instructional practices associated with positive language and literacy outcomes for adolescents, in general, apply to ELs as well, and practices for ELs in elementary and middle school continue to be relevant in high school instruction. Research has identified nine promising practices with clear relevance to the education of ELs in high school:

- Develop academic English and its varied grammatical structures and vocabulary intensively as part of subject-matter learning.

- Integrate oral and written language instruction into content-area teaching.

- Provide regular structured opportunities to develop written language skills.

- Develop the reading and writing abilities of ELs through text-based, analytical instruction using a cognitive strategies approach.

- Provide direct and explicit comprehension strategy instruction.

- Provide opportunities for extended discussion of text meaning and interpretation.

- Foster student motivation and engagement in literacy learning.

- Provide regular peer-assisted learning opportunities.

- Provide small group instructional opportunities to students struggling in areas of literacy and English language development.

LTELs who are struggling in school but are very proficient in spoken English need rigorous, intensive, and relevant support in small groups, supported by teachers who can offer the kind of attention they need to discover how language works in texts.

\section{Promising Practices in Context}

The promise of the practices listed above is evidenced in a recent study of six high schools in the northeastern region of the United States (Castellón et al., 2015). This report from the Schools to Learn From study, provides detailed descriptions of instructional practices, lessons, materials, and student work, all based on interviews with administrators and teachers. Schools selected for the study included those with higher-than-average EL high school graduation and postsecondary entry rates. The teachers at these schools created opportunities for extended practice on rigorous course materials. Teachers did not just assign materials, but provided the ongoing support students needed to deal with the materials' language demands. Characteristics that the six schools had in common included

- missions that guided hiring of staff, scheduling, course programming, professional learning, and partnerships with community organizations; 
- goal of continuous improvement;

- shared responsibility for students' success;

- support for student needs and capacities; and

- valuing cultural and linguistic diversity among their students.

\section{Conclusion and Resources}

Although the Promising Futures report did not explicitly address nonformal educational settings such as community-based organizations, positive youth development programs, sports programs, faith-based organizations, and other settings, these are important partners in ELs' educational journey. All children and youth can become bilingual or multilingual given the appropriate opportunities. The ability to communicate and to learn in more than one language is universal and is an asset that can enhance cognitive control, social and cultural competence, educational outcomes, and work skills in a global economy. Research also reveals that many institutions responsible for early childhood and pre- $\mathrm{K}$ to 12 education are failing to provide DLLs and ELs with appropriate opportunities to learn. To learn more about how to support ELs, visit the National Clearinghouse for English Language Acquisition as well as the U.S. Department of Education's Office of English Lanquage Acquisition.

\section{References}

Boyson, B. A., \& Short, D. (2003). Secondary school newcomer programs in the United States. Center for Research on Education, Diversity and Excellence, University of California, Santa Cruz.

Burke, A. (2015). Suspension, expulsion, and achievement of English learner students in six Oregon districts (REL report 2015-094). U.S. Department of Education, Institute of Education Sciences, National Center for Education Evaluation and Regional Assistance, Regional Educational Laboratory Northwest. http://ies.ed.gov/ncee/edlabs/regions/northwest/pdf/REL 2015094.pdf

Callahan, R. M. (2005). Tracking and high school English learners: Limiting opportunity to learn. American Educational Research Journal, 42(2), 305-328. https://doi.org/10.3102/00028312042002305

Castellón, M., Cheuk, T., Greene, R., Mercado-Garcia, D., Santos, M., Skarin, R., \& Zerkel, L. (2015). Schools to learn from: How six high schools graduate English language learners college and career ready. Stanford University Graduate School of Education.

DeGarmo, D. S., \& Martinez, C. R., Jr. (2006). A culturally informed model of academic well-being for Latino youth: The importance of discriminatory experiences and social support. Family Relations, 55(3), 267-278. https://doi.org/10.1111/j.1741-3729.2006.00401.x 
Dupoux, E., Peperkamp, S., \& Sebastián-Gallés, N. (2010). Limits on bilingualism revisited: Stress "deafness" in simultaneous French-Spanish bilinguals. Cognition, 114(2), 266-275. https://doi.org/10.1016/j.cognition.2009.10.001

Eccles, J. S. (2008). Agency and structure in human development. Research in Human Development, 5(4), 231-243. https://doi.org/10.1080/15427600802493973

Egalite, A. J., \& Kisida, B. (2016). School size and student achievement: A longitudinal analysis. School Effectiveness and School Improvement, 27(3), 1-12. https://doi.org/10.1080/09243453.2016.1190385

Espinosa, L. M. (2013). PreK-3rd: Challenging common myths about dual language learners. Foundation for Child Development. https://www.fcd-us.org/prek-3rd-challenging-common-myths-about-duallanguage-learners-an-update-to-the-seminal-2008-report/

Gordon, K. R. (2016). High proficiency across two languages is related to better mental state reasoning for bilingual children. Journal of Child Language, 43(2), 407-424. https://doi.org/10.1017/S0305000915000276

Kim, J. I., \& Viesca, K. M. (2016). Three reading-intervention teachers' identity positioning and practices to motivate and engage emergent bilinguals in an urban middle school. Teaching and Teacher Education, 55, 122-132. https://doi.org/10.1016/j.tate.2016.01.003

Leithwood, K., \& Jantzi, D. (2009). A review of empirical evidence about school size effects: A policy perspective. Review of Educational Research, 79(1), 464-490. https://doi.org/10.3102/0034654308326158

Meisel, J. M. (2011). First and second language acquisition: Parallels and differences. Cambridge University Press.

Menken, K. (2013). Emergent bilingual students in secondary school: Along the academic language and literacy continuum. Language Teaching, 46(4), 438-476. https://doi.org/10.1017/S0261444813000281

National Academies of Sciences, Engineering, and Medicine. (2019). The promise of adolescence: Realizing opportunity for all youth. The National Academies Press. https://doi.org/10.17226/25388

Nield, R. (2009). Falling off track during the transition to high school: What we know and what can be done. The Future of Children, 19(1), 53-76. https://doi.org/10.1353/foc.0.0020

Olsen, L. (2010). Reparable harm: Fulfilling the unkept promise of educational opportunity for California's long term English learners. Californians Together. http://www.ctdev.changeagentsproductions.org/wpcontent/uploads/2015/01/ReparableHarm2ndedition.pdf 
Journal of Youth Development | http://jyd.pitt.edu/ | Vol. 15 Issue 3 DOI 10.5195/jyd.2020.947 Dual Language Learning and Educational Success

Ortiz-Mantilla, S., Choudhury, N., Alvarez, B., \& Benasich, A. A. (2010). Involuntary switching of attention mediates differences in event-related responses to complex tones between early and late Spanish-English bilinguals. Brain Research, 1362, 78-92.

https://doi.org/10.1016/j.brainres.2010.09.031

Rumberger, R., Gándara, P., \& Merino, B. (2006). Where California's English learners attend school and why it matters. UC LMRI Newsletter, 15(2), 1-3. https://escholarship.org/uc/item/4j32m4jg

Suárez-Orozco, C., Suárez-Orozco, M.M., \& Todorova, I. (2008). Learning a new land: Immigrant students in American society. Harvard University Press.

Umansky, I. M., \& Reardon, S. F. (2014). Reclassification patterns among Latino English learner students in bilingual, dual immersion, and English immersion classrooms. American Educational Research Journal, 51(5), 879-912. https://doi.org/10.3102/0002831214545110

U.S. Department of Education, Office of English Language Acquisition. (2018, September). Fast Facts: National and state-level high school graduation rates for English learners. https://www.ncela.ed.gov/files/fast facts/GraduationRatesFactSheet.pdf

Valentino, R. A., \& Reardon, S. F. (2015). Effectiveness of four instructional programs designed to serve English learners: Variation by ethnicity and initial English proficiency. Educational Evaluation and Policy Analysis, 374), 612-637. https://doi.org/10.3102/0162373715573310

Valdés, G. (2001). Learning and not learning English: Latino students in American schools. Teachers College Press.

Walqui, A., Koelsch, N., Hamburger, L., Gaarder, D., Insaurralde, A., Schmida, M., \& Weiss, S. (2010). What are we doing to middle school English learners? Findings and recommendations for change from a study of California EL programs (Research Report). WestEd. 